\title{
On-site Assessment of Environmental and Sanitary Qualities of Rainwater Harvesting System (RWH) in a Rural Community in Benin City, Nigeria
}

\section{ISOKEN, H. IGBINOSA; OSAHON V. OSEMWENGIE}

\author{
Department of Environmental Management and Toxicology, Faculty of Life Sciences, University of Benin, Private Mail Bag 1154, Benin \\ City, Nigeria \\ *Corresponding author email: isoken.igbinosa@uniben.edu
}

\begin{abstract}
Around fifty percent of individuals living in underdeveloped countries lack safe drinking water and sanitation. Occasionally their water sources get contaminated with their waste leading to an elevated level of distress. The improvement of water supply, sanitation, hygiene and management of water resources can hugely prevent up to one-tenth of the global disease burden. On-site assessment of environmental and sanitary qualities of rainwater harvesting system $(\mathrm{RWH})$ in households was carried out using a structured questionnaire. The structural assessment of the rainwater harvesting system showed that corrugated iron sheet was the roof type used in all sites surveyed. Also all the rainwater harvesting (RWH) system surveyed was found to have gutters, although the condition of the gutters varied: good (15\%), fair $(65 \%)$ and poor $(20 \%)$. The harvested rainwater reservoir was mainly made of concrete $(90 \%)$ with subsurface submerge in the ground. On-site assessment of the sanitary location of the RWH system showed that $5 \%$ were located near a septic tank and another $5 \%$ in flooded area. The harvested rainwater was used for several domestic purposes including drinking. All respondent agreed that they use rainwater for washing while $10 \%$ of the respondent agreed that they drink the harvested rainwater. The maintenance culture of RWH system owners was investigated. Sixty-five percent $(65 \%)$ of respondent agreed that they have first diverters devise installed in the rainwater harvesting system. Ten percent $(10 \%)$ of respondent has never cleaned their storage reservoir. Of the remaining respondents, $50 \%$ cleaned their reservoir once a year while $25 \%$ clean twice a year. The rainwater harvesting system in the study area lack basic environmental and structural requirements which pose potential health risk to individual who rely on the source of water for potable use. (C) JASEM
\end{abstract}

\section{http://dx.doi.org/10.4314/jasem.v20i2.12}

KEYWORDS: Water shortage, Health risk, Water quality, Roof-top, Rainwater

\section{Introduction}

Health related concern associated with the quality of drinking water in developing countries has been on the increase. A recent report by WHO/UNICEF shows that about 780 million people in the developing world lack access to potable water majorly as a result of microbiological and chemical contamination (WHO/UNICEF, 2012). The accessibility of adequate and potable water for household use is an enormous challenge for rural households in developing countries (Vilane and Mwendera, 2011). About $75 \%$ of all diseases in developing countries results from polluted drinking water, hence provision of safe drinking water is an utmost necessity (TWAS, 2002). About $50 \%$ of people living in developing countries have no access to safe drinking water and $73 \%$ lack sanitation, sometimes their waste contaminate their drinking water sources resulting to a high level of suffering. The improvement of water supply, sanitation, hygiene and management of water resources can hugely prevent up to one-tenth of the global disease burden (Vilane and Mwendera, 2011).
Man has sought out different ways to mitigate the global challenge of water shortage in order to meet daily need. One of the alternative sources explored by man is rainwater harvesting (Eletta and Oyeyipo, 2008). Generally, rainwater harvesting can be regarded as any human practice that consciously captures and stores rainwater for future purpose (DTU, 1999). Rainwater harvesting is still the only source of potable water for rural communities where there are no watery networks and supplemental source where watery network is available. Rainwater harvesting is one of the most promising alternatives for supplying water in the face of increasing water scarcity and escalating demand. Rainwater harvesting presents an opportunity for the augmentation of water supplies allowing the same time for self-reliance and sustainability. However, the primary concern regards to the use of rainwater, for either non-potable or potable use, is quality. The quality of water collected in a rainwater harvesting system can be affected by many factors. These factors includes the nature of the catchment system, the roof materials, environmental pollution from industries, automobiles and anthropogenic activities, the presence of particles,

*Corresponding author email: isoken.igbinosa@uniben.edu 
debris and dropping from birds or rodents on roofs and the type of storage materials used for harvested rainwater.

Private and public water supplies in Nigeria are not adequately examined by regulatory agencies such as National Environmental Standards and Regulations Enforcement Agency (NESREA) and National Agency for Food and Drugs Administration and Control (NAFDAC) thereby, resulting to the distribution of substandard and unsafe drinking water (Anake et al., 2014). However, taking cognizance of the lack of potable water in rural communities, which has made the inhabitants to go for cheap or free source of water like rainwater harvesting for their domestic use, it has become imperative to investigate the rainwater harvesting systems used by these rural dwellers. Therefore, this research work was carried out to investigate structural and environmental qualities of rainwater harvesting system in a rural community in Benin City, Nigeria.

\section{MATERIALS AND METHODS}

Study Area: This study was carried out in Ugbihioko village in Benin City, Edo State, Nigeria. Benin City has an estimated population of $1,147,188$ according to 2006 census and the capital of Edo State in Southern Nigeria. It is a city approximately 25 miles north of the Benin River. Ugbihioko is situated at upper Ekehuan road in Egor Local Government Area of Edo State with coordinate of latitude $6^{\circ} 19.2341^{\prime}$ and longitude $5^{\circ} 34.10094$. It is a small community in midst of four other communities namely: Uzebu, Utagban, Evbuotubu and Oghede community. The water supply source of the community is rainwater collected from house roof-top into a reservoir, though, recently a few inhabitants has begun to construct boreholes. With the level of modernization, most houses still use the ancient means of water collection (harvested rainwater).

Data Collection Methods: Data was collected from households with evident rainwater harvesting system installed in the house. Houses without observable rainwater harvesting system were excluded from the study. Data was collected using quantitative data collection tool: a survey questionnaire. The survey questionnaire was adapted from that used in a previous study (Mosley, 2005) and practice of rainwater harvesting, perceptions of water quality. The survey questionnaire was pretested for validity. The checklist designed by the researchers with input from experts in the field and a checklist used in an earlier study (Mosley, 2005) provided a tool for assessing the state of the rainwater harvesting system. Informed consent was obtained from each respondent before the conduct of interviews and administration of questionnaire.
Data Analysis : The completed questionnaires were screened for completeness, coded and entered by the researcher into the Statistical Package for Social Sciences (SPSS) version 16.0 (SPSS Inc, Chicago IL 60606- 6412). Descriptive statistical analysis was employed for the data obtained. Statistical analysis of differences between proportions was carried out using chi-square test. Statistical significance was set at $p<$ 0.05 for all values of the chi square test.

\section{RESULTS AND DISCUSSION}

On-site assessment of rainwater harvesting system: From the questionnaire analysis it was revealed that corrugated iron roofing sheet is mostly used in household in Ugbohioko village for rainwater harvesting. All 20 sites surveyed, use corrugated iron sheet in the rainwater harvesting system. All the rainwater harvesting (RWH) system surveyed was found to have gutters. Fifteen percent $(15 \%)$ of the gutter was in good condition, $65 \%$ were categorized as fair while $20 \%$ were in poor condition. Overhanging vegetation was found in $65 \%$ of the RWH system. The harvested rainwater reservoir was mainly made of concrete (90\%) with subsurface submerge in the ground. The remaining $10 \%$ were made of poly vinyl chloride. Thirty percent of the storage reservoir was characterized to be in poor condition because there were evidence of visible crack and dillapilitating appearance. The storage reservoir had lid in $90 \%$ of them. The lid covering the reservoir was categorized as either metal, zinc, plastic or wood. The metal lids were $12 / 20(60 \%)$, zinc lid $2 / 20(10 \%)$, plastic $2 / 20$ $(10 \%)$, wooden lid $2 / 20(10 \%)$. On-site assessment of the sanitary location of the RWH system showed that $5 \%$ were located near a septic tank and another $5 \%$ in flooded area. Table 1 summarizes on site assessment of rainwater harvesting system in Ugbhioko village.

The use of rainwater by household: The harvested rainwater was used for several domestic purposes and for drinking as stated by some individual during the administration of the questionnaire. All respondent agreed that they use rainwater for washing while $10 \%$ of the respondent agreed that they drink the harvested rainwater. Those that drink the harvested rainwater also agreed that they use the rainwater for cooking, washing clothes and bathing. Five percent of respondent use the water for cooking, washing and bathing only. The respondent who uses the rainwater for bathing and washing only were $9 \%$. Figure 1 shows the different use of harvested rainwater by household respondents. All respondent claimed that they have never experienced or perceived any ailment associated with the use of harvested rainwater. 


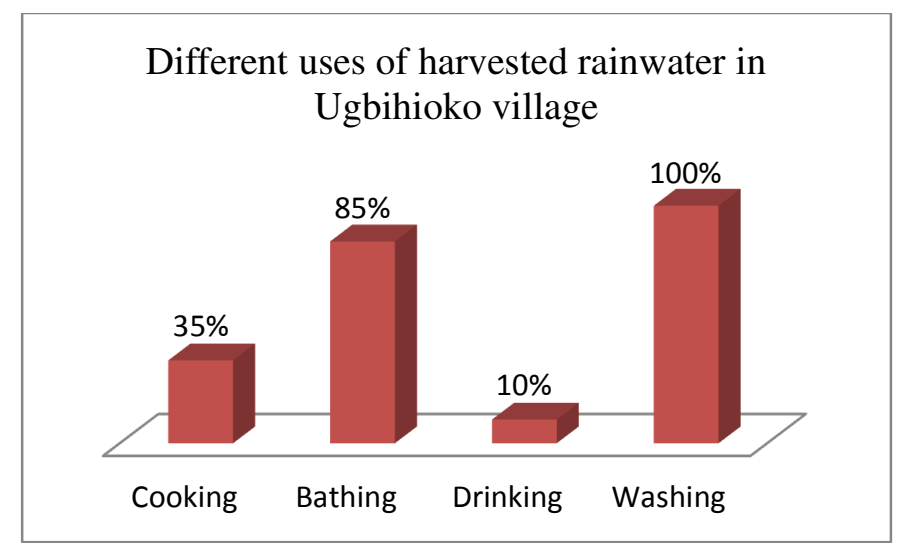

Fig 1. Percentage frequency of the different uses of harvested rainwater in Ugbiohoko village

Maintenance of rainwater harvesting system and age of storage reservoir: The maintenance cultures of RWH system owners were investigated. Sixty-five percent of respondent agreed that they have first diverters devise installed in the rainwater harvesting system. Thirty-five percent of respondent agreed that they do not have first diverters devise installed in their RWH system. All respondent agreed that they have never cleaned the roof (catchment surface) of their RWH system. Ten percent of respondent has never cleaned their storage reservoir. Of the remaining respondents, $50 \%$ cleaned their reservoir once a year while $25 \%$ clean twice a year. Most of the storage reservoir was more than 10 years of age according to information from $80 \%$ of respondents, $10 \%$ were less than 5 years of age and another $10 \%$ between 5-10 years of age.

Construction of RWH system and water treatment: All respondent agreed that water scarcity was the reason for the construction of rainwater harvesting system. Ninety-five percent of respondent do not treat the harvested rainwater before use, only $5 \%$ treat water prior use and the method of treatment is the use of alum.

Table 1: Structural Quality of Rainwater Harvesting System in Ugbiohoko Village

\begin{tabular}{lclc}
\hline Roof and gutter & Frequency $(100)$ & Storage Reservoir & Frequency (100) \\
\hline $\begin{array}{l}\text { Roof type } \\
\text { Corrugated iron sheet }\end{array}$ & $20(100)$ & $\begin{array}{l}\text { Type } \\
\text { Concrete }\end{array}$ & \\
Others & $0(0)$ & PVC & $18(90)$ \\
& & & $2(10)$ \\
Overhead vegetation & $13(65)$ & Appearance & \\
$\begin{array}{l}\text { Present } \\
\text { Absent }\end{array}$ & $7(35)$ & Good & $3(15)$ \\
& & Fair & $11(55)$ \\
Completeness of system & $20(100)$ & Poor & $6(30)$ \\
Gutter present & & Lid & \\
& & Present & \\
Condition of gutter & Absent & $18(90)$ \\
Good condition & $3(15)$ & Lid material & $2(10)$ \\
Fair condition & $13(65)$ & Metal & \\
Poor condition & $4(20)$ & Zinc & $12(60)$ \\
& & Plastic & $2(10)$ \\
Sanitary location & & Wood & $2(10)$ \\
Septic tank + & & Tap & $2(10)$ \\
Refuse dump + Flooded area & $2(10)$ & Present & \\
& & Absent & $2(10)$ \\
\hline
\end{tabular}

Corrugated iron sheet was the roof type used by all rainwater harvesting system surveyed. Overhanging vegetation was found in rainwater harvesting system in the study area. The presence of overhanging vegetation in rainwater harvesting system could impair the quality of harvested rainwater. This could be a source of contamination of the harvested rainwater, as birds or rodents droppings and dead leaves on roof tops are washed by rainfall into the harvested rainwater reservoir. Animal droppings and decaying leaves serves as source of organic matter in the stored water and this may impart smell, colour in the stored rainwater (Van Metre and Mahler, 2003; Hart and White, 2006), and microbial proliferation in the stored rainwater. Possible contamination of the rainwater with animal wastes and organic matter 
which may result in health risks if the rainwater is not treated prior to consumption as a drinking water source.

The type of storage materials for harvested rainwater has effect on the quality of water. Majority of the storage reservoir of harvested rainwater in the studied area was made of concrete. These reservoir were submerged in the ground, this is in contrast to what was observed in Swaziland (Vilane and Mwendera, 2011). The merits of subsurface reservoir include temperature balance, structural support of the soil and protection from vandalism. However, the detection and repair of fault in this type of storage container is difficult. Also, expansion and contraction of soil can lead to structural damage, leakage and crack if proper reinforcement of the tank is absent (Barnes et al., 2010).

The storage reservoir in the study area lack tap for extraction of water, the inhabitants use fetcher to extract water from the reservoir. The fetcher, if not properly maintained, could be source of contamination of the stored water. Surface tank has the advantage of easy accessibility and maintenance, easy extraction of water through a tap. The location of harvested rainwater near a septic tank and flooded area was observed in a few RWH systems in the study, as this is against the US Environmental Protection Agency's. To avoid the associated health risk of contamination, a storage reservoir must not be sited lesser than 50 feet to a source of contamination, such as a septic tank. Septic tank has the ability to diffuse into underground water sources including underground water reservoir, although it depends on the material the underground water storage reservoir is made up of and the distance of the reservoir to a septic tank.

The harvested rainwater in the study area was used for several purposes including drinking. This is similar to an observation in Australia where $13 \%$ of households use rainwater as their main source of drinking water. The drinking of rainwater has been reported in Sri lanka and Ethiopa (Devi et al., 2012), However the data are far higher than those reported in this study. Rainwater can be used as a source for hot water services, laundry, toilet flushing, or gardening. These uses represent lower risks to public health than drinking. Almost all respondent in the study do not treat rainwater prior to use, it is most vital to treat harvested rainwater from storage reservoir. Disinfection of the harvested rainwater, which includes filtration and/or ozone or UV disinfection, is necessary if rainwater is to be used as potable water. The level of treatment needed depends, to a great extent, on whether the intended uses require portability (such as drinking, food preparation, bathing, and washing dishes or hands) or do not (such as toilet flushing, laundry and irrigation). Obviously, rainwater that is used for potable purposes must receive a higher level of treatment than water that is harvested for irrigation (Mendez et al., 2011).

The use of first-flush diverters was found by most of the RWH system users. This enhances the quality of water entering the storage reservoir and may reduce the need for subsequent treatment (Singwane and Kunene, 2010). Although some of the first diverters were not properly installed, as most were manually installed. First flush diverters system was absolutely absent in some RWH system in the study area. The absence of first flush diverters or improperly installed first flush system implies that rainwater not diverted go on to contaminate stored water in reservoir.

The cleaning of the RWH system was carried out by the owners in the study, although at different duration. This observation is similar to finding elsewhere (Rodrigo et al., 2010). The cleaning of water storage reservoir was of low occurrence in the study, this is similar to what was observed in South Australia (Rodrigo et al., 2010). An annual cleaning of storage reservoir has been recommended in previous study (Coombes and Abott, 2010). The average duration that the reservoir was constructed and in use is similar to a study reported in Australia (Rodrigo et al., 2010). It is important to note that prolong use of storage reservoir will require that attention be paid to the maintenance of the reservoir to prevent it from being an additional source of hazard to users. General increase in family size or anthropogenic activities may necessitate addition of more storage reservoir to mitigate with ever increasing water demand.

Conclusion: The study shows that the rainwater harvesting system in Ugbihioko village lack vital structural and environmental qualities. Improper or incomplete structural enhancement of RWH system may serves as route of contamination of stored harvested rainwater. From the study, it was observed that the harvested rainwater was used for potable purposes including drinking. It therefore shows that the inhabitants are at potential risk that uses the harvested rainwater as a source of water supply. Treatment of water prior to use is highly recommended. There is need for Governmental parastatal to educate the populace on the requirement of constructing rainwater harvesting system. This study, suggest that there is the need for public awareness of the inherent associated risk of improper installment of rainwater harvesting system. Continuous monitoring of structural and environmental status of rainwater harvesting system is highly recommended.

Acknowledgment: The authors wish to thank Ugbihioko community for their participation in the survey.

\section{REFERENCES}


Anake, WU; Benson, NU; Akinsiku, AA; EhiEromosele, CO; Adeniyi, IO (2014). Assessment of trace metals in drinking water and groundwater sources in Ota, Nigeria. Int. J. Scienti. Res. Pub. 4: $1-4$.

Barnes, D; Collins, C; Ziff S (2010). The bio-sand filter, siphon filter and rainwater harvesting: strategic recommendations for new water treatment technologies and safe water storage to pure home water. Available online at: http://web. mit. edu/ watson/ Docs/ student\% 20Reports/Ghana.pdf (Accessed 12/5/2013)

Coombes, P; Abott, S (2010). An ideal and sustainable water supply. Available online at: http:// rain harvesting.com.au/rainwater knowledge-centrerainwater-harvesting (Assessed 12/5/2013).

Devi, R; Diboch, B; Singh, V (2012). Rainwater harvesting practices: key concept of energy-water linkage for sustainable development. Sci. Res. Essays. 7: 538-43.

DTU. (1999). "Report Al - Current Technology for Storing Domestic Rainwater (Part 1)" Development Technology Unit (DTU), Department of Engineering, University of Warwick, Coventry, UK $<$ http://www2.warwick.ac.uk/fac/sci/eng/researc h/dtu/pubs/ reviewed/rwh/ eu/ a1. pdf $>$ Accessed 4/19/2009.

Eletta, OA; Oyeyipo, JO (2008). Rain Water Harvesting: Effect of Age of Roof on Water Quality. Int. J. Appl. Chem. 4: 157-162.

Hart, PC; White D (2006). Water quality and construction materials in rainwater catchments across Alaska. J. Environ. Eng. Sci. 5: 19-25.

Mendez, CB; Bae, S; Chambers, B; Fakhreddine, S; Gloyna, T; Keithley, S; Untung, L; Barrett, ME; Kinney, K; Kirisits, MJ (2011). Effect of roof material on water quality for rainwater harvesting systems - additional physical, chemical, and microbiological data. Texas Water Development Board (TWDB) Report. Published and distributed by the Texas Water Development Board, Capitol Station Austin, Texas. Pg 47.

Mosley, L (2005). Quality of rain water harvesting system. SOPAC Miscellaneous report 579. Available online at:
http://www.pacificwater.org/userfile/MR0579.pd f. Accessed 4/3/2015

Rodrigo, S; Sinclair, M; Leder, K (2010). A survey of the characteristics and maintenance of rain water tanks in urban areas of South Australia. Water Sci. Technol. 61: 1569.

Singwane, SS; Kunene, SG (2010). Viability of rain water harvesting in supplying domestic water in rural areas of Swaziland; a case of Mpaka community. J. Sustainable Devel. Africa. 12: 90109.

Third World Academy of Science (TWAS 2002).Safe drinking water the need, the problem, solutions and an action plan. Report of the Third World Academy of Sciences. Third World Academy of Sciences (TWAS), Trieste, Italy. Available online at: http://twas. ictp. it/ publications/ twas reports/safedrinkingwater.pdf (Accessed 12/5/2013)

Van Metre, PC; Mahler, BJ (2003). The contribution of particles washed from rooftops to contaminant loading to urban streams. Chemosph. 52: 17271741.

Vilane, BRT; Mwendera, EJ (2011). An inventory of rainwater harvesting technologies in Swaziland. Afr. J. Agric. Res. 6: 1313-132.

WHO-UNICEF. (2000). Global water supply and sanitation assessment 2000 Report. Available online at:

http://www.who.int/water_sanitation_health/Glo bassessment/GlobalT OC.htm. 